\title{
Free Vibration Analysis of Rhombic Plate with Central Crack
}

\author{
Mohammad Sikandar Azam, Vinayak Ranjan and Bipin Kumar \\ Department of Mechanical Engineering, Indian Institute of Technology (Indian School of Mines), Dhanbad- \\ 826004 , India.
}

(Received 29 January 2015; accepted 5 May 2016)

In this paper, free vibration analysis of rhombic plate with pre-existing central crack has been done using the finite element method. The Mindlin theory of plate has been used in the process of investigation. The following six boundary conditions at the edges of the plate have been considered. They are simply supported at all edges (SSSS), clamped at all edges (CCCC), free at all edges (FFFF), clamped-simply supported (CSSC), clamped-free (CFFC), and clamped-free-simply supported (CSFS). Effects of crack length on natural frequencies of rhombic plate with different skew angles i.e. $15^{\circ}, 30^{\circ}, 45^{\circ}, 60^{\circ}$ have been studied. It is observed that percentage drop in fundamental frequency due to presence of central crack in the rhombic plate increases with an increase in skew angle for CCCC, SSSS, and CSSC edge conditions at a given crack ratio (non-dimensional crack length). Under the CFFC, CSFS, and FFFF edge conditions, percentage drop in natural frequency of rhombic plate is very small for crack ratio of 0.2 at different skew angles. In case of the CFFC edge condition of the rhombic plate, percentage drop in fundamental frequency is within $0.7 \%$ at all skew angles and with all crack ratios considered. Some of the results obtained by the present method have been compared with the published results. Most of the results obtained are novel for rhombic crack plate.

\section{INTRODUCTION}

Applications of skew plates are found in various types of engineering structures such as aircraft wings, bridge decks, ship decks, and rail and road vehicles. Manufacturing processes and loading conditions may induce a crack in a plated structure, which significantly alters the dynamic behaviour of the plate. Therefore, dynamic analysis of skew plate is crucial for design engineers. A substantial amount of literature is available on free vibration of intact skew plates. Leissa ${ }^{1}$ presented a monograph on vibration of plate followed by review articles ${ }^{2-4}$ on previous work carried out in the field of plate vibration. Different methods have been applied to solve the problem of free vibration of skew plates under simply supported edge condition. Raju and Hinton ${ }^{5}$ examined natural frequencies and mode shape of the rhombic Mindlin plate under various boundary conditions containing simply supported and clamped edges using quadrilateral isoparametric plate element. They explained the effect of skew angles and thickness ratio on mode frequency of the plate. Durvasula ${ }^{6,7}$ applied the Ritz method and the Galerkin method to determine natural frequencies under simply supported and clamped edge conditions. Liew and $\mathrm{Lam}^{8}$ adopted Rayleigh-Ritz method along with twodimensional orthogonal plate function to work out natural frequencies of the skew plate under varied edge conditions and at different skew angles. Liew et al. ${ }^{9}$ delved into the phenomenon of vibration of skew plates based on Mindlin plate theory under simply supported edge condition and for two opposite edges simply supported with the other two clamped. Stress singularities at the obtuse corner were first used by Basu et al. ${ }^{10}$ They modelled the quadrant at $60^{\circ}$ simply supported skew plate using hierarchical Legendre elements of the fifth order. Mc Gee ${ }^{11,12}$ tried to get to the bottom of vibration of cantilever skew plate considering the plate to be thick and with singularity at the corner. Huang et al. ${ }^{13}$ investigated the plate vibration considering stress singularities at the obtuse corner of a simply supported skew plate using Ritz method. They applied displacement function consisting of algebraic polynomial and the corner function that takes care of corner stress singularity. Mc Gee et al. ${ }^{14}$ studied the effect of stress singularity at the corner on the vibration of skew (rhombic) plate with different combinations of simply supported and clamped edges conditions. Langrangian function was obtained by the Ritz method. Transverse displacement function was constructed by making use of the algebraic polynomial and corner function, which account for kinematic boundary condition and stress singularity at the hinged -hinged and clamped-hinged corners. Further Mc Gee et al. ${ }^{15}$ investigated the singularity effect on vibration behaviour of skew plate under free and simply supported edge conditions. Woo et al. ${ }^{16}$ determined natural frequencies and mode shapes of a skew Mindlin plate using P-version of the finite element method under different sets of boundary conditions and discussed the effect of skew angle, aspect ratio, and cutout dimension on the frequency parameter. Zhou and Zheng ${ }^{17}$ came out with accurate results on vibration of skew plate by utilizing moving least square - Ritz method. Results, thus obtained, were found close to the available results in literature but certain mode frequencies deviated from the data presented by Mc Gee et al., ${ }^{12}$ Hung et al., ${ }^{13}$ and Mc Gee et al. ${ }^{15}$ Mizusawa and Kondo ${ }^{18}$ investigated vibration of the skew plate with linearly varied thickness along longitudinal axis by using the spline spring method. By making use of 
the differential quadrature method as well as polynomial and harmonic functions, Malekzadeh and Karami ${ }^{19}$ analysed free vibration of skew plate with linearly varying thickness in both directions. Based on linear and small strain theory of elasticity in three dimensions, Zhou et al. ${ }^{20}$ studied the vibration of thick skew plate. Eigenvalue equation was obtained from energy functional using the Ritz method. Displacement function was formed by multiplying Chebyshev polynomial series with boundary function. Lai et al. ${ }^{21}$ adopted DSC-element method to analyse vibration of skew plates by using the first order shear deformation theory for continuous and discontinuous boundaries. Wang and $\mathrm{Wu}^{22}$ studied the free vibration of skew under 14 sets of boundary condition with free edges by applying modified differential quadrature method (DQM). The authors observed that problems were extremely sensitive to grid spacing and to the method of applying the multiple boundary condition at large skew angle. Wang et al. ${ }^{23}$ further investigated the skew plate vibration phenomenon by utilizing a new version of DQM under eight sets of edge conditions consisting of free, simply supported, and clamped.

The studies referred above focus to vibration characteristic of intact skew plate. Vibration of cracked rectangular and square plates was studies by various researchers but the literature on vibration of cracked skew plate is merely available. Stahl and Keer, ${ }^{24}$ Huang and Leissa, ${ }^{25}$ Huang et al., ${ }^{26}$ Bachene et al., ${ }^{27}$ and Liew et al. ${ }^{31}$ studied the vibration of cracked rectangular and square plate with central crack, side crack and inclined crack under different boundary conditions by different methods that include the Ritz method, Rayleigh-Ritz method and finite element method. Recently, Israr et al., ${ }^{28}$ Ismail and Cartmell, ${ }^{29}$ and Joshi et al. ${ }^{30}$ presented closed form solution for the vibration of cracked rectangular plate. This paper deals with the effect of central crack on natural frequencies of skew plate under six different combinations of edge conditions by the finite element method.

\section{METHODOLOGY}

\subsection{Formulation of Rectangular Plate with Crack}

Let us consider an isotropic square plate with central crack in Cartesian coordinate system as shown in Fig. 1. The crack is continuous line through crack. Formulations of the displacement and the finite element equation are based upon the Mindlin plate's theory, which take into account shear deformation and rotary inertia. Let $u, v, w$ are the displacement in $x$, $y$, and $z$ direction respectively, then

$$
\begin{aligned}
& u(x, y, z)=z \theta_{x}(x, y) \\
& v(x, y, z)=z \theta_{y}(x, y) \\
& w(x, y, z)=w_{z}(x, y)
\end{aligned}
$$

where $\theta_{x}$ and $\theta_{y}$ are the rotations of the mid surface normal in $\mathrm{X}-\mathrm{z}$ and $\mathrm{y}-\mathrm{z}$ planes respectively.

We assume that crack path is parallel to one side of the plate and the crack stops at the end of each element as depicted

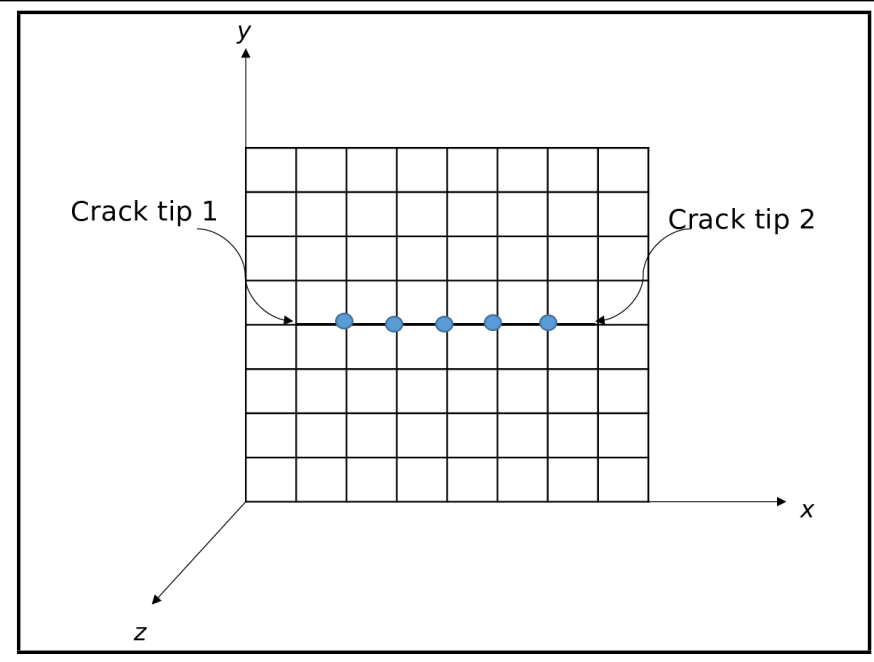

Figure 1. Discretization of plate (crack aligned with mesh, circle nodes are enriched with jump function).

in Fig. 1. The discretization of the plate may be represented by $^{27,32}$

$$
\{\delta\}=\sum_{i}\left[N_{i}\right]\left\{\delta_{i}\right\}+\sum_{j} H(x)\left[N_{j}\right]\left\{\delta_{j}^{\prime}\right\} .
$$

In Eq. (4), $N_{i}$ and $\delta_{i}$ are the classical shape function and the classical nodal displacements, respectively, at node $i$. Next, $j$ represents the nodes at discontinuity, and $\delta_{j}^{\prime}$ are the nodal displacements to be enriched and $H(x)$ is a discontinuity function. Based upon Mindlin plate theory, finite element formulation can be written as

$$
\{\delta\}=\left\{\begin{array}{l}
w_{z} \\
\theta_{x} \\
\theta_{y}
\end{array}\right\}=\sum_{I}\left[N_{i}\right]\left\{\delta_{i}\right\}+\sum_{J} H\left[N_{j}\right]\left\{\delta_{j}^{\prime}\right\} .
$$

$I$ is set of all nodal points on the plate, $J$ is set of all nodes of elements located on the discontinuity and

$$
\begin{gathered}
\left\{\delta_{i}\right\}=\left\{\begin{array}{c}
w_{z i} \\
\theta_{x i} \\
\theta_{y i}
\end{array}\right\} ; \\
\left\{\delta_{j}^{\prime}\right\}=\left\{\begin{array}{c}
w_{z j}^{\prime} \\
\theta_{x j}^{\prime} \\
\theta_{y j}^{\prime}
\end{array}\right\} .
\end{gathered}
$$

The strain field $\varepsilon_{x x}, \varepsilon_{y y}, \gamma_{x y}, \gamma_{x z}$, and $\gamma_{y z}$ can be written in matrix form as in Eq. (7) (See on top of the next page). The Eq. (7) can be symbolically written as follows

$$
\{\varepsilon\}=\left[B_{i}\right]\left\{\delta_{i}\right\}+\left[B_{j}^{\prime}\right]\left\{\delta_{j}^{\prime}\right\} ;
$$

where $\left[B_{j}^{\prime}\right]=H\left[B_{j}\right]$.

The stress field can be written as

$$
\{\sigma\}=[D]\left[B_{i}\right]\left\{\delta_{i}\right\}+[D]\left[B_{j}^{\prime}\right]\left\{\delta_{j}^{\prime}\right\}
$$

where $[D]$ represents elastic coefficient matrix and $\{\sigma\}$ is generalized stress.

The potential energy of any element $e$ of the plate is given by

$$
U^{e}=\frac{1}{2} \int_{A_{e}}\{\sigma\}^{T}\{\varepsilon\} d A ;
$$




$$
\varepsilon_{i j}=\left\{\begin{array}{l}
\varepsilon_{x x} \\
\varepsilon_{y y} \\
\gamma_{x y} \\
\gamma_{x z} \\
\gamma_{y z}
\end{array}\right\}=\sum_{I}\left[\begin{array}{ccc}
0 & \frac{\partial\left[N_{i}\right]}{\partial x} & 0 \\
0 & 0 & \frac{\partial\left[N_{i}\right]}{\partial y} \\
0 & \frac{\partial\left[N_{i}\right]}{\partial y} & \frac{\partial\left[N_{i}\right]}{\partial x} \\
\frac{\partial\left[N_{i}\right]}{\partial x} & {\left[N_{i}\right]} & 0 \\
\frac{\partial\left[N_{i}\right]}{\partial x} & 0 & {\left[N_{i}\right]}
\end{array}\right]\left\{\begin{array}{l}
w_{z i} \\
\theta_{x i} \\
\theta_{y i}
\end{array}\right\}+\sum_{J}\left[\begin{array}{ccc}
0 & H \frac{\partial\left[N_{j}\right]}{\partial x} & 0 \\
0 & 0 & H \frac{\partial\left[N_{j}\right]}{\partial y} \\
0 & H \frac{\partial\left[N_{j}\right]}{\partial y} & H \frac{\partial\left[N_{j}\right]}{\partial x} \\
H \frac{\partial\left[N_{j}\right]}{\partial x} & H\left[N_{j}\right] & 0 \\
H \frac{\partial\left[N_{j}\right]}{\partial x} & 0 & H\left[N_{j}\right]
\end{array}\right]\left\{\begin{array}{c}
w_{z j}^{\prime} \\
\theta_{x j}^{\prime} \\
\theta_{y j}^{\prime}
\end{array}\right\} .
$$

$$
\begin{array}{r}
U^{e}=\frac{1}{2} \int_{A_{e}}\left(\left\{\delta_{i}\right\}^{T}\left[B_{i}\right]^{T}[D]+\left\{\delta_{j}^{\prime}\right\}^{T}\left[B_{j}^{\prime}\right]^{T}[D]\right) \\
\left(\left[B_{i}\right]\left\{\delta_{i}\right\}+\left[B_{j}^{\prime}\right]\left\{\delta_{j}^{\prime}\right\}\right) d A
\end{array}
$$

where $A_{e}=$ element area.

Equation (11) can be further written as

$$
U^{e}=\frac{1}{2}\left\{\left\{\delta_{i}\right\}^{T}\left\{\delta_{j}^{\prime}\right\}^{T}\right\}\left[K^{e}\right]\left\{\begin{array}{c}
\delta_{i} \\
\delta_{j}^{\prime}
\end{array}\right\}
$$

where

$$
\left[K^{e}\right]=\left[\begin{array}{ll}
\int_{A}\left[B_{i}\right]^{T}[D]\left[B_{i}\right] d A & \int_{A}\left[B_{i}\right]^{T}[D]\left[B_{j}^{\prime}\right] d A \\
\int_{A}\left[B_{j}^{\prime}\right]^{T}[D]\left[B_{i}\right] d A & \int_{A}\left[B_{j}^{\prime}\right]^{T}[D]\left[B_{j}^{\prime}\right] d A
\end{array}\right] ;
$$

or

$$
\left[K^{e}\right]=\left[\begin{array}{ll}
{\left[K_{i i}^{e}\right]} & {\left[K_{i j}^{e}\right]} \\
{\left[K_{j i}^{e}\right]} & {\left[K_{j j}^{e}\right]}
\end{array}\right]
$$

where $\left[K_{i i}^{e}\right]$ is classical stiffness matrix, $\left[K_{i j}^{e}\right]$, and $\left[K_{j i}^{e}\right]$ are coupling stiffness matrix, and $\left[K_{j j}^{e}\right]$ is enriched stiffness matrix.

The kinetic energy for an element of the plate is given by

$$
\left[T^{e}\right]=\frac{1}{2} \int\left\{\dot{\delta}_{e}\right\}^{T} \rho\left\{\dot{\delta}_{e}\right\} h d A ;
$$

where $\dot{\delta}_{e}$ is the first derivative of the displacement field w.r.t time and $\rho$ is the material density of the plate.

Similarly, by proper transformation Eq. (14) may also be written as

$$
T^{e}=\frac{1}{2}\left\{\left\{\dot{\delta}_{i}\right\}^{T}\left\{\dot{\delta}_{j}^{\prime}\right\}^{T}\right\}\left[M^{e}\right]\left\{\begin{array}{c}
\dot{\delta}_{i} \\
\dot{\delta}_{j}^{\prime}
\end{array}\right\} ;
$$

where $\left[M^{e}\right]$ of the element is given as

$$
\left[M^{e}\right]=\left[\begin{array}{cc}
\int_{A_{e}}\left[N_{i}\right] \rho\left[N_{i}\right] h d A & \int_{A_{e}}\left[N_{i}\right] \rho H\left[N_{j}\right] h d A \\
\int_{A_{e}} H\left[N_{j}\right] \rho\left[N_{i}\right] h d A & \int_{A_{e}} H\left[N_{j}\right] \rho H\left[N_{j}\right] h d A
\end{array}\right]
$$

or

$$
\left[M^{e}\right]=\left[\begin{array}{ll}
{\left[M_{i i}^{e}\right]} & {\left[M_{i j}^{e}\right]} \\
{\left[M_{j i}^{e}\right]} & {\left[M_{j j}^{e}\right]}
\end{array}\right] .
$$

Here, $\left[M_{i i}^{e}\right]$ is the classical mass matrix, $\left[M_{i j}^{e}\right]$ and $\left[M_{j i}^{e}\right]$ are the coupling mass matrix, and $\left[M_{j j}^{e}\right]$ is enriched mass matrix.

\subsection{Oblique Boundary Transformation}

Figure 2 shows the geometry and co-ordinate system of rhombic plate where $a$ and $b$ are equal. Next, $c$ indicates the crack length, and $\beta$ is the skew angle of the skew plate.

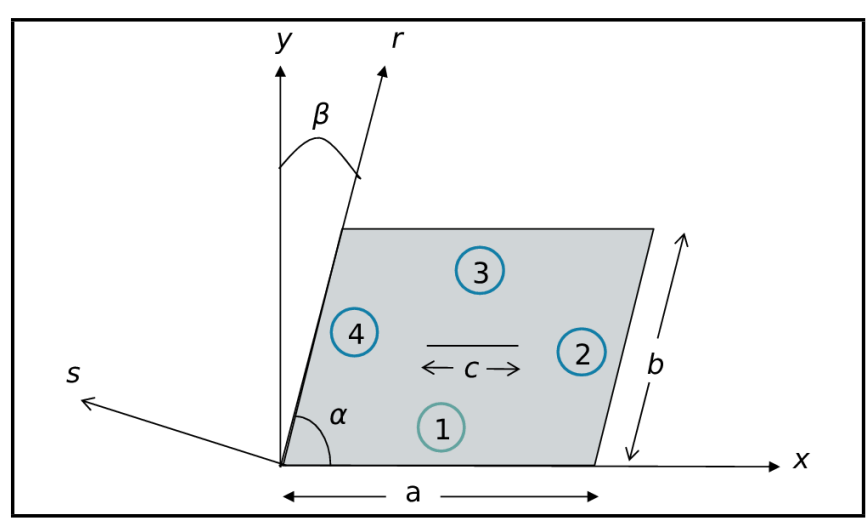

Figure 2. Geometry and co-ordinate system of rhombic plate.

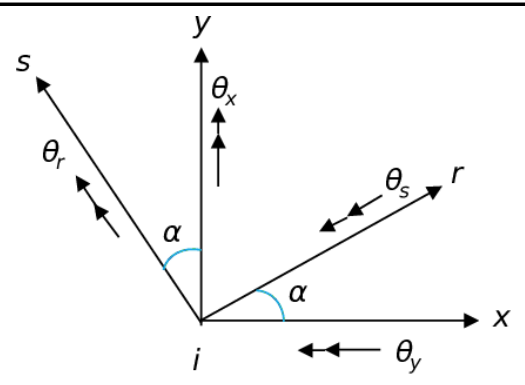

Figure 3. Global and local skew co-ordinate system for oblique boundary transformation.

For skew plate, both the edges may not be parallel to the global axes $x$ and $y$. To specify the boundary conditions at such edges the local displacements $w, \theta_{r}$, and $\theta_{s}$ as shown in Fig. 3 may be used.

Here, $\theta_{r}$ and $\theta_{s}$ are average rotations of the normal to the reference plane and are tangential and normal to the oblique edge. It is necessary to transform the element matrices corresponding to global axes $(x, y)$ along which the boundary conditions are specified.

Using $\theta_{x}, \theta_{y}, \theta_{r}$, and $\theta_{s}$ vector as shown in Fig. 3, where $\alpha=90^{\circ}-\beta$, the displacement transformation for a node $i$ on the oblique boundary is given by

$$
\begin{array}{r}
\{\delta\}=\left\{\begin{array}{c}
w_{z} \\
\theta_{x} \\
\theta_{y}
\end{array}\right\}= \\
{\left[\begin{array}{ccc}
1 & 0 & 0 \\
0 & \cos \alpha & -\sin \alpha \\
0 & \sin \alpha & \cos \alpha
\end{array}\right]\left\{\begin{array}{l}
w_{z} \\
\theta_{r} \\
\theta_{s}
\end{array}\right\}=[R]\left\{\begin{array}{c}
w_{z} \\
\theta_{r} \\
\theta_{s}
\end{array}\right\} ;}
\end{array}
$$

where $[R]$ is transformation matrix. This matrix is valid for three degrees of freedom per node. For nodes which are not located on the oblique boundary, it becomes a unit matrix. 
The element stiffness matrix and the mass matrix are then arrived at after mapping into the $(r, s)$ co-ordinate system as

$$
\begin{gathered}
{\left[\mathcal{K}^{e}\right]=\int_{A_{e}}[R]^{T}\left[K^{e}\right][R] d A ;} \\
{\left[\mathcal{M}^{e}\right]=\int_{A_{e}}[R]^{T}\left[M^{e}\right][R] d A .}
\end{gathered}
$$

The free vibration equation of the skew plate with crack can be written as

$$
[\mathcal{K}]-\{\lambda\}[\mathcal{M}]\{\delta\}_{r, s}=0 ;
$$

where $\{\lambda\},[\mathcal{K}]$, and $[\mathcal{M}]$ are eigenvalues, assembled stiffness matrix, and assembled mass matrix, respectively.

\section{NUMERICAL RESULTS AND DISCUSSION}

The approach discussed in preceding section has been applied to study free vibration of a rhombic plate with central crack as shown in Fig. 2 under different combinations of edge conditions. Skew plate having all the edges equal in length $(a=b)$ is called a rhombic plate. Natural frequencies are presented in terms of non-dimensional frequency parameters formulated as

$$
\Omega=\omega a^{2} \sqrt{\frac{\rho h}{\mathcal{D}}} ;
$$

where $\mathcal{D}$ is the bending rigidity given by $E h^{3} /\left[12\left(1-\nu^{2}\right)\right]$. Further, $\rho, E$, and $\nu$ are density, Young 's modulus, and Poisson's ratio, respectively, of the plate material. Next, $h$ represents the thickness of the plate.

The present problem uses density $\rho$, Young's modulus $E$, and Poisson's ratio $\nu$ of the plate material equal to $7800 \mathrm{~kg} / \mathrm{m}^{3}$, $200 \mathrm{GPa}$, and 0.3 respectively. Throughout, the analysis thickness to length ratio $(h / a)$ of the plate has been kept equal to 0.001 . Both intact skew plate and cracked skew plates with central crack parallel to the edge along $x$ axis of the plate have been studied under six different combination of edge conditions as described in Table 1 with reference to Fig. 2. Crack length in terms of crack ratio has been used throughout the present investigation, which is defined as ratio of crack length $c$ and edge length $a$ along $x$ axis.

\subsection{Validation of Results}

First, frequency parameters for intact rhombic plate are tabulated under different set of edge conditions. Table 1 displays the comparison of first five frequency parameters obtained through the present formulation with the results achieved by Wang and $\mathrm{Wu}^{22}$ for rhombic intact plate with skew angles $15^{\circ}$, $30^{\circ}, 45^{\circ}$, and $60^{\circ}$ under the FFFF edge condition. The frequency parameters $\Omega=\omega a^{2} \sqrt{\rho h / \mathcal{D}}$ are in very good agreement. The frequency parameters of FFFF rhombic plate with skew angle $30^{\circ}$ and $60^{\circ}$ are also compared with those obtained by Singh and Chakerverty. ${ }^{34}$ Large deviation in frequency parameter can be observed at large skew angle. Clearly, results obtained by them ${ }^{34}$ are not converged at high skew angle. Table 3 shows that frequency parameters of the rhombic plate with different skew angles under SSSS edge condition agree well with the ones from Wang et al., ${ }^{23}$ Woo et al., ${ }^{16}$ Liew et al., ${ }^{9}$ Huang et al., ${ }^{13}$ and Bardell. ${ }^{33}$ For the skew angle of $60^{\circ}$, first mode frequency of the rhombic plate is slightly more than that obtained by Wang et al. ${ }^{23}$ and Huang et al. ${ }^{13}$ but slightly less than that obtained by Woo et al., ${ }^{16}$ Liew et al., ${ }^{9}$ and Bardell. ${ }^{33}$ Differences in results are more for mode 5 but the present results are close to those given by Bardell $^{33}$ for all modes. Results of intact rhombic plate under CCCC edge conditions are compared with those obtained from the investigation of Wang et al., ${ }^{23}$ Woo et al., ${ }^{16}$ Liew et al., ${ }^{9}$ Raju and Hinton, ${ }^{5}$ and Bardell. ${ }^{33}$ The comparisons are shown in Table 4. Good agreement between the results can be seen. From the above discussion, it can be concluded that present model provides very good results for intact rhombic plate with different skew angle under different edge conditions. However, it still requires confirmation regarding crack plate.

To validate the present model for crack plate, simply supported plate with central crack is considered. Table 5 shows that the frequency parameters of a square plate with central crack under simply supported edge condition are in very close agreement with those obtained by Bechene et al. ${ }^{27}$ and Stahl and $\mathrm{Keer}^{24}$ and agree well with those given by Huang et al., ${ }^{26}$ and Liew et al. ${ }^{31}$ Huang et al. ${ }^{26}$ and Liew et al. ${ }^{31}$ have adopted Ritz method and domain decomposition method, respectively, to investigate the vibration of crack plate. Their results are slightly on the higher side. Although results for six and seven modes are also available in literature for few cases but the comparisons are made up to $5^{\text {th }}$ mode only for the sake of uniformity. Apart from the five lowest natural frequencies used for validation, results for the sixth and seventh mode frequencies are also presented in Tables 2 to 5 .

This paper presents new sets of results of frequency parameters for cracked skew plates with different skew angles under SSSS, FFFF, CCCC, CFFC, CSSC, and CSFS edge conditions as described in Tables 6 to 9 .

\subsection{Intact Rhombic Plate}

This section, first, analyses the effect of skew angle on natural frequencies of rhombic plate when the skew angle changes from $15^{\circ}$ to $60^{\circ}$ with an interval of $15^{\circ}$. Figure 4 shows the effect of skew angle on fundamental frequency of rhombic intact plate. An increase in skew angle from $0^{\circ}$ to $60^{\circ}$ results in an increase in fundamental frequencies of rhombic plate under SSSS, CCCC, CSSC, and CSFC edge conditions while fundamental frequency of rhombic plate decreases under FFFF edge conditions. In case of CFFC rhombic plate, fundamental frequency remains almost the same with variation of skew angle. The increase in frequency parameter with an increase in skew angle is greater when the skew angle goes beyond $45^{\circ}$ under SSSS, CCCC, and CSSC edge conditions of the rhombic plate. Again, it can be observed from Tables 6 to 9 that higher modes frequencies (mode 2 onward) of the rhombic plate under SSSS, CCCC, CSSC, and CSFC conditions go up with an increase in skew angle. In case of CFFC edge condition, higher mode (mode 3 onward) frequencies go on increasing with an increase 
Table 1. Description of six edge conditions.

\begin{tabular}{|c|c|c|c|c|}
\hline Edge conditions & Edge 1 & Edge 2 & Edge 3 & Edge 4 \\
\hline SSSS & Simply supported & Simply supported & Simply supported & Simply supported \\
\hline FFFF & Free & Free & Free & Free \\
\hline CCCC & Clamped & Clamped & Clamped & Clamped \\
\hline CFFC & Clamped & Free & Free & Clamped \\
\hline CSSC & Clamped & Simply supported & Simply supported & Clamped \\
\hline CSFS & Clamped & Simply supported & Free & Simply supported \\
\hline
\end{tabular}

Table 2. Comparison of frequency parameters $\Omega=\omega a^{2} \sqrt{\rho h / \mathcal{D}}$ for rhombic intact plate under FFFF edge condition.

\begin{tabular}{||c|c|c|c|c|c|c|c|c||}
\hline $\begin{array}{c}\text { Skew angle } \\
\beta^{\circ}\end{array}$ & Reference & \multicolumn{7}{|c|}{ Modes } \\
\cline { 3 - 9 } & & 1 & 2 & 3 & 4 & 5 & 6 & 7 \\
\hline 15 & Present & 12.757 & 20.291 & 27.106 & 30.288 & 39.289 & 57.549 & 63.667 \\
\hline & 22 & 12.761 & 20.292 & 27.108 & 30.298 & 39.304 & & \\
\hline 30 & Present & 11.528 & 22.645 & 26.652 & 35.359 & 43.915 & 51.673 & 69.387 \\
\hline & 22 & 11.531 & 22.646 & 26.659 & 35.364 & 43.933 & & \\
\hline & 34 & 11.690 & 22.926 & 27.254 & 36.512 & 46.214 & & \\
\hline 45 & Present & 10.499 & 24.032 & 27.761 & 41.766 & 51.521 & 61.518 & 66.930 \\
\hline & 22 & 10.499 & 24.034 & 27.763 & 41.771 & 51.537 & & \\
\hline 60 & Present & 9.779 & 22.265 & 39.296 & 39.854 & 62.674 & 68.575 & 89.716 \\
\hline & 22 & 9.779 & 22.268 & 39.316 & 39.859 & 62.686 & & \\
\hline & 34 & 9.824 & 23.140 & 40.033 & 52.669 & 78.110 & & \\
\hline
\end{tabular}

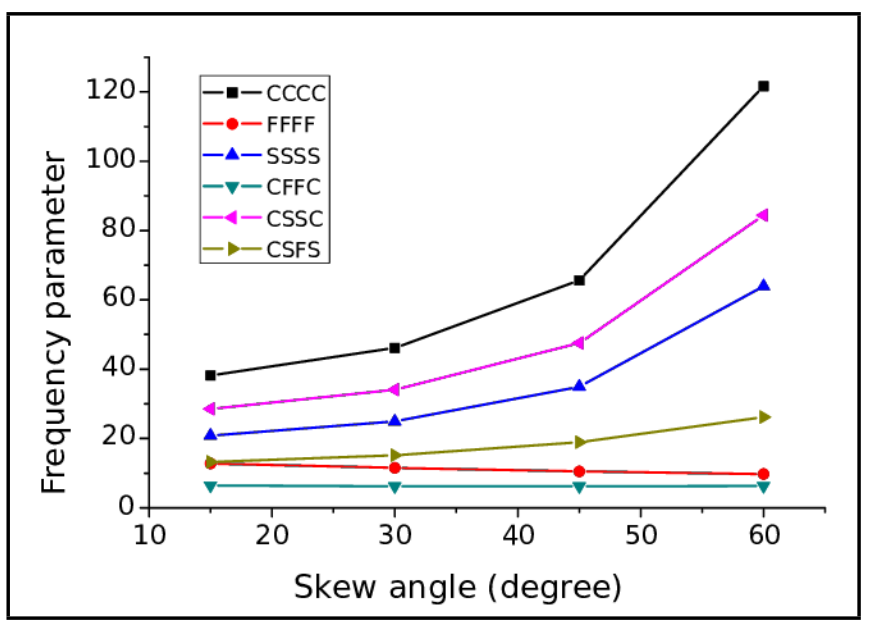

Figure 4. Effect of skew angle on fundamental frequency of intact rhombic plate.

in skew angle. However higher modes frequencies of FFFF rhombic plate such as the $2^{\text {nd }}, 3^{\text {rd }}, 4^{\text {th }}, 6^{\text {th }}$, and $7^{\text {th }}$ modes, show a combination of increasing and decreasing pattern of variation in natural frequencies with an increase in skew angle as shown in Fig. 5. The $5^{\text {th }}$ mode frequency of FFFF rhombic plate increases smoothly with increase in skew angle.

A change in skew angle of rhombic plate results in change in the mass of the plate as well as change in the shape of the plate. Mass of the plate directly affects its natural frequency whereas a change in the shape of the plate alters the stiffness, which ultimately changes the natural frequencies of the plate. The magnitude of the change in stiffness due to change in shape (change in skew angle) also depends upon the edge condition. Figure 4 also exhibits the effect of edge conditions on fundamental frequency of the rhombic plate. Under the CFFC edge condition, rhombic plate has the lowest fundamental frequency and under the CCCC edge conditions, it has the highest fundamental frequency among the six different combinations of edge conditions considered in this paper. This observation is true for all the skew angles of the plate considered for the analysis,

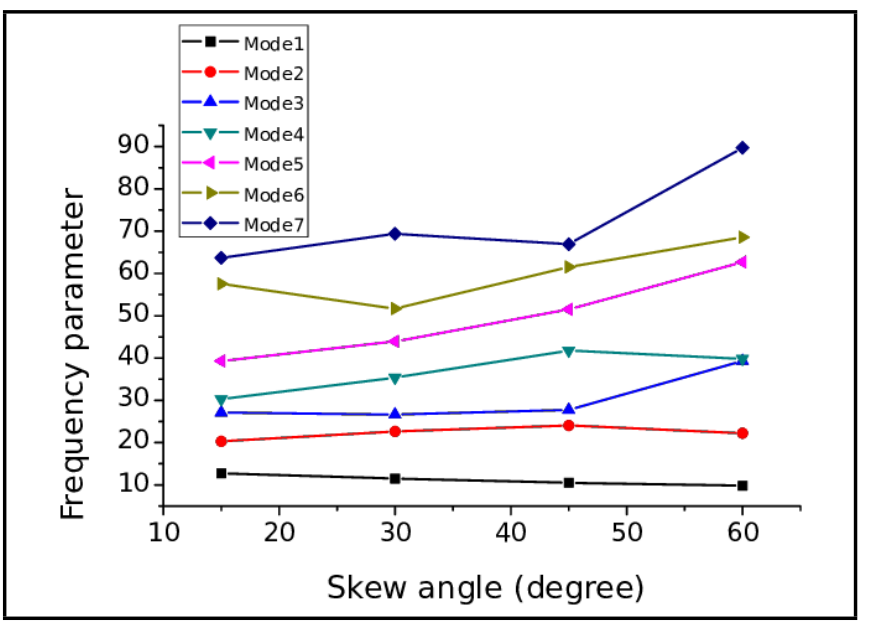

Figure 5. Effect of skew angle on natural frequencies of FFFF rhombic plate.

such as, $15^{\circ}, 30^{\circ}, 45^{\circ}$, and $60^{\circ}$. The effect of edge conditions can also be studied from Tables 6 to 9 . It is noticed that natural frequencies increase due to higher constraint. Frequency parameter under FFFF edge condition is lowest among SSSS, FFFF, and CCCC whereas frequency parameter of CCCC edge condition is the highest. This is due to the fact that more edge constraints result in an increase in stiffness of the plate causing an increase in natural frequencies.

\subsection{Rhombic Plate with Crack}

Tables 6 to 9 present the seven lowest natural frequencies for CCCC, CFFC, CSSC, FFFF, CSFS, and SSSS rhombic cracked plate with skew angles $15^{\circ}, 30^{\circ}, 45^{\circ}$, and $60^{\circ}$. As expected, the natural frequency decreases with an increase in crack length of rhombic plates, irrespective of the skew angles and edge conditions. The decrease in natural frequencies due to the formation of crack and further decrease in frequency due to an increase in crack ratio are attributed to reduction in local stiffness of the plate. It is further noticed that a reduction in natural frequencies of a cracked rhombic plate is not proportional to the crack ratio. A small crack with a ratio $c / a=0.2$ 
Table 3. Comparison of frequency parameters $\Omega=\omega a^{2} \sqrt{\rho h / \mathcal{D}}$ for rhombic intact plate under SSSS edge condition.

\begin{tabular}{|c|c|c|c|c|c|c|c|c|}
\hline $\begin{array}{c}\text { Skew angle } \\
\beta^{\circ}\end{array}$ & Reference & \multicolumn{7}{|c|}{ Modes } \\
\cline { 2 - 9 } & & 1 & 2 & 3 & 4 & 5 & 6 & 7 \\
\hline 15 & Present & 20.858 & 48.192 & 56.089 & 79.010 & 103.981 & 108.857 & 120.432 \\
\hline & 23 & 20.868 & 48.205 & 56.107 & 79.043 & 104.000 & & \\
\hline & 16 & 20.873 & 48.204 & 56.130 & 79.0457 & 104.0029 & & \\
\hline & 9 & 20.871 & 48.205 & 56.115 & 79.0457 & 103.998 & & \\
\hline & 13 & 20.868 & 48.205 & 56.107 & 79.0427 & 104.000 & & \\
\hline 30 & Present & 24.900 & 52.624 & 71.720 & 83.808 & 122.782 & 122.802 & 140.471 \\
\hline & 23 & 24.899 & 52.638 & 71.711 & 83.829 & 122.820 & & \\
\hline & 16 & 25.049 & 52.638 & 72.067 & 83.901 & 122.890 & & \\
\hline & 9 & 24.964 & 52.638 & 71.871 & 83.858 & 122.820 & & \\
\hline & 13 & 24.899 & 52.638 & 71.711 & 83.829 & 122.820 & & \\
\hline & Present & 34.935 & 66.266 & 100.287 & 107.446 & 140.766 & 168.275 & 185.066 \\
\hline & 23 & 34.755 & 66.277 & 100.250 & 107.010 & 140.800 & & \\
\hline & 16 & 35.403 & 66.292 & 100.654 & 109.302 & 141.372 & & \\
\hline & 9 & 35.333 & 66.277 & 100.429 & 108.323 & 140.802 & & \\
\hline & 13 & 34.749 & 66.277 & 100.250 & 107.040 & 140.800 & & \\
\hline & Present & 63.929 & 104.912 & 148.011 & 196.191 & 208.840 & 248.963 & 293.411 \\
\hline 60 & 23 & 62.331 & 104.950 & 147.650 & 196.290 & 205.350 & & \\
\hline & 16 & 68.258 & 105.230 & 150.230 & 199.990 & 217.820 & & \\
\hline & 9 & 66.303 & 104.970 & 148.740 & 196.410 & 213.790 & & \\
\hline & 13 & 62.409 & 104.950 & 147.670 & 196.290 & 205.860 & & \\
\hline & 33 & 64.818 & 104.960 & 148.320 & 196.290 & 210.660 & & \\
\hline & & & & & & \\
\hline
\end{tabular}

Table 4. Comparison of frequency parameters $\Omega=\omega a^{2} \sqrt{\rho h / \mathcal{D}}$ for rhombic intact plate under CCCC edge condition.

\begin{tabular}{|c|c|c|c|c|c|c|c|c|}
\hline \multirow{2}{*}{$\begin{array}{c}\text { Skew angle } \\
\beta^{\circ}\end{array}$} & \multirow{2}{*}{ Reference } & \multicolumn{7}{|c|}{ Modes } \\
\hline & & 1 & 2 & 3 & 4 & 5 & 6 & 7 \\
\hline \multirow[t]{5}{*}{15} & Present & 38.186 & 72.896 & 82.618 & 109.558 & 138.970 & 145.149 & 157.569 \\
\hline & 23 & 38.187 & 72.896 & 82.618 & 109.560 & 138.970 & & \\
\hline & 16 & 38.175 & 72.902 & 82.665 & 109.645 & 139.310 & & \\
\hline & 9 & 38.186 & 72.895 & 82.616 & 109.558 & 138.970 & & \\
\hline & 5 & 38.215 & 73.242 & 83.003 & 110.342 & 141.826 & & \\
\hline \multirow[t]{4}{*}{30} & Present & 46.092 & 81.602 & 105.166 & 119.251 & 164.983 & 165.315 & 186.178 \\
\hline & 23 & 46.089 & 81.601 & 105.170 & 119.250 & 164.990 & & \\
\hline & 33 & 46.090 & 81.601 & 105.170 & 119.250 & 164.990 & & \\
\hline & 9 & 46.089 & 81.599 & 105.160 & 119.250 & 164.980 & & \\
\hline \multirow[t]{5}{*}{45} & Present & 65.651 & 106.507 & 148.327 & 157.249 & 196.793 & 229.510 & 248.421 \\
\hline & 23 & 65.643 & 106.490 & 148.310 & 157.230 & 196.770 & & \\
\hline & 16 & 65.707 & 106.848 & 150.312 & 159.174 & 203.041 & & \\
\hline & 9 & 65.652 & 106.491 & 148.316 & 157.264 & 196.795 & & \\
\hline & 5 & 65.781 & 107.579 & 151.597 & 158.802 & 204.992 & & \\
\hline \multirow[t]{4}{*}{60} & Present & 121.634 & 177.710 & 231.729 & 291.496 & 304.732 & 354.605 & 408.631 \\
\hline & 23 & 121.640 & 177.720 & 231.750 & 291.520 & 304.780 & & \\
\hline & 33 & 121.650 & 177.720 & 231.750 & 291.520 & 304.810 & & \\
\hline & 9 & 121.790 & 177.710 & 231.890 & 291.790 & 305.410 & & \\
\hline
\end{tabular}

reduces the first seven frequency parameters by less than $3 \%$ in relation to an intact CSSC rhombic plate with a skew angle of $15^{\circ}$. On the other hand, a crack ratio of 0.5 decreases the frequency parameter by up to $16 \%$ for the $5^{\text {th }}$ mode of the CSSC skew plate. At this point of discussion percentage reduction or drop in natural frequency, $\Pi$ is formulated as

$$
\Pi=\frac{\Omega_{\text {uncracked }}-\Omega_{\text {cracked }}}{\Omega_{\text {uncracked }}} \times 100
$$

As the skew angle of rhombic plate increases, the percentage drop in fundamental frequency increases under SSSS, CCCC, and CSSC edge conditions for a particular crack ratio as shown in Figs. 6 to 10. For small cracks $(c / a \approx 0.2)$, the percentage drop in fundamental frequency is very small in case of CFFC, CSFS and FFFF rhombic plate at all skew angles as observed in Fig. 6. When the crack ratio increases to 0.8 , the percentage drop in fundamental frequency of CSFS and FFFF rhombic plate becomes obvious at higher skew angles as shown in
Fig. 10. It is further noted that percentage drop in fundamental frequency for CFFC rhombic plate is negligibly small (within $0.7 \%$ ) at all skew angles and all crack ratios considered in this paper. It can be observed in Figs. 6 and 7 that the line of SSSS edge condition of the rhombic plate crosses the line of the CCCC edge condition. Plates under SSSS and CCCC edge conditions, having skew angle about $47^{\circ}$, will have equal percentage change in fundamental frequency due to the development of crack having a crack ratio of 0.2. Similarly, plates under SSSS and CCCC edge conditions having skew angle about $32^{\circ}$ will also have the equal percentage change in fundamental frequency due to the development of crack having crack ratio of 0.4. The trend of crossing the line of SSSS edge conditions with CCCC edge condition is not observed with the crack ratios of $0.5,0.6$, and 0.8 .

Apart from the development of crack and skew angle, changes in natural frequencies also depend upon the mode 
M. S. Azam, et al.: FREE VIBRATION ANALYSIS OF RHOMBIC PLATE WITH CENTRAL CRACK

Table 5. Comparison of frequency parameters $\Omega=\omega a^{2} \sqrt{\rho h / \mathcal{D}}$ for for square plate with central crack parallel to one edge of the plate.

\begin{tabular}{|c|c|c|c|c|c|c|c|c|c|}
\hline \multirow{2}{*}{$\begin{array}{c}\text { Edge } \\
\text { condition }\end{array}$} & \multirow[t]{2}{*}{ Reference } & \multirow{2}{*}{$\begin{array}{l}\text { Crack } \\
\text { ratio }\end{array}$} & \multicolumn{7}{|c|}{ Modes } \\
\hline & & & 1 & 2 & 3 & 4 & 5 & 6 & 7 \\
\hline \multirow[t]{33}{*}{ SSSS } & 24 & 0 & 19.739 & 49.348 & 49.348 & 78.957 & 98.696 & & \\
\hline & 31 & & 19.740 & 49.350 & 49.350 & 78.960 & 98.700 & & \\
\hline & 27 & & 19.739 & 49.348 & 49.348 & 78.955 & 98.698 & & \\
\hline & Present & & 19.738 & 49.347 & 49.347 & 78.953 & 98.697 & 98.697 & 128.252 \\
\hline & & & & & & & & & \\
\hline & 26 & 0.1 & 19.660 & 49.340 & 49.350 & 78.960 & 97.790 & & \\
\hline & Present & & 19.621 & 49.323 & 49.332 & 78.924 & 97.433 & 98.696 & 128.207 \\
\hline & & & & & & & & & \\
\hline & 24 & 0.2 & 19.305 & 49.170 & 49.328 & 78.957 & 93.959 & & \\
\hline & 31 & & 19.380 & 49.160 & 49.310 & 78.810 & 94.690 & & \\
\hline & 27 & & 19.305 & 49.181 & 49.324 & 78.945 & 93.893 & & \\
\hline & 26 & & 19.330 & 49.190 & 49.320 & 78.950 & 94.130 & & \\
\hline & Present & & 19.308 & 49.183 & 49.321 & 78.949 & 93.912 & 98.685 & 127.714 \\
\hline & & & & & & & & & \\
\hline & 26 & 0.3 & 18.850 & 48.500 & 49.240 & 78.890 & 89.730 & & \\
\hline & Present & & 18.909 & 48.630 & 49.262 & 78.912 & 90.593 & 98.675 & 125.262 \\
\hline & & & & & & & & & \\
\hline & 24 & 0.4 & 18.279 & 46.624 & 49.032 & 78.602 & 85.510 & & \\
\hline & 31 & & 18.440 & 46.440 & 49.040 & 78.390 & 86.710 & & \\
\hline & 27 & & 18.278 & 46.635 & 49.032 & 78.600 & 85.450 & & \\
\hline & 26 & & 18.290 & 46.650 & 49.030 & 78.610 & 85.560 & & \\
\hline & Present & & 18.281 & 46.637 & 49.031 & 78.612 & 85.459 & 98.614 & 112.313 \\
\hline & & & & & & & & & \\
\hline & 24 & 0.5 & 17.706 & 43.031 & 48.697 & 77.733 & 82.155 & & \\
\hline & 31 & & 17.850 & 42.820 & 48.720 & 77.440 & 83.010 & & \\
\hline & 27 & & 17.707 & 43.042 & 48.685 & 77.710 & 82.108 & & \\
\hline & 26 & & 17.720 & 43.060 & 48.690 & 77.720 & 82.180 & & \\
\hline & Present & & 17.710 & 43.049 & 48.680 & 77.715 & 82.111 & 95.498 & 98.380 \\
\hline & 24 & 0.6 & 17.193 & 37.978 & 48.223 & 75.581 & 79.588 & & \\
\hline & 31 & & 17.330 & 37.750 & 48.260 & 75.230 & 80.320 & & \\
\hline & 27 & & 17.180 & 37.987 & 48.214 & 75.579 & 79.556 & & \\
\hline & 26 & & 17.190 & 37.990 & 48.220 & 75.590 & 79.600 & & \\
\hline & Present & & 17.180 & 37.989 & 48.218 & 75.580 & 79.559 & 85.485 & 97.983 \\
\hline
\end{tabular}

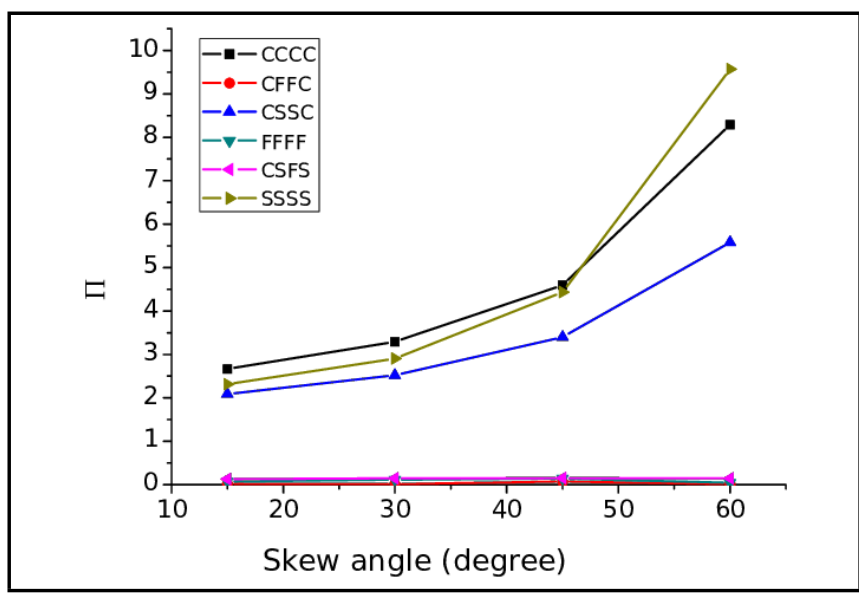

Figure 6. Effect of skew angles on percentage drop in fundamental frequency of rhombic plate for crack ratio of 0.2 .

number and edge conditions of the rhombic plate. Percentage change or drop in fundamental frequency due to a change in crack ratio from zero to 0.8 is the maximum under the SSSS edge conditions and minimum under the CFFC edge condition as shown in Fig. 10. If we look at $15^{\circ}$ rhombic plate under CCCC edge conditions, percentage drop in natural frequency is the maximum $(48.59 \%)$ in second mode and minimum (12\%) in third mode out of seven lowest natural frequencies for a crack ratio of 0.8 .

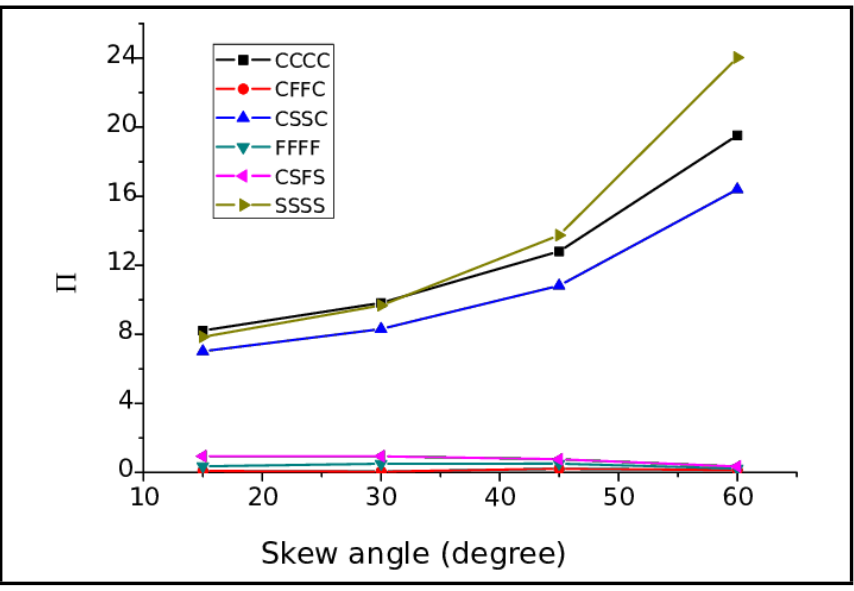

Figure 7. Effect of skew angles on percentage drop in fundamental frequency of rhombic plate for crack ratio of 0.4 .

The percentage drop in natural frequency may be used for an estimation of the magnitude of crack present in rhombic plate under different edge conditions and at different skew angles. For example, a drop in natural frequency of $19.52 \%$ in the CCCC rhombic plate with the skew angle of $60^{\circ}$ may be estimated at a crack ratio of 0.4 (Fig. 11). 
Table 6. Seven non-dimensional frequency parameters $\Omega=\omega a^{2} \sqrt{\rho h / \mathcal{D}}$ of a thin rhombic plate with central horizontal crack under different boundary conditions $\left(h / a=0.001, \nu=0.3, \beta=15^{\circ}\right)$.

\begin{tabular}{|c|c|c|c|c|c|c|c|c|}
\hline \multirow{2}{*}{$\begin{array}{c}\text { Edge } \\
\text { conditions }\end{array}$} & \multirow{2}{*}{$\begin{array}{l}\text { Crack } \\
\text { ratio }\end{array}$} & \multicolumn{7}{|c|}{ Modes } \\
\hline & & 1 & 2 & 3 & 4 & 5 & 6 & 7 \\
\hline \multirow[t]{6}{*}{$\mathrm{CCCC}$} & 0 & 38.186 & 72.896 & 82.618 & 109.558 & 138.970 & 145.149 & 157.569 \\
\hline & 0.2 & 37.168 & 72.720 & 82.167 & 109.107 & 135.308 & 141.242 & 156.696 \\
\hline & 0.4 & 35.051 & 68.493 & 77.206 & 107.397 & 124.118 & 137.752 & 140.196 \\
\hline & 0.5 & 34.101 & 60.296 & 74.934 & 105.261 & 119.731 & 123.380 & 138.478 \\
\hline & 0.6 & 33.395 & 50.828 & 73.725 & 100.787 & 115.938 & 116.988 & 135.214 \\
\hline & 0.8 & 32.749 & 37.473 & 72.622 & 83.357 & 111.424 & 112.830 & 130.064 \\
\hline \multirow[t]{6}{*}{ CFFC } & 0 & 6.443 & 24.780 & 25.248 & 47.499 & 64.269 & 68.382 & 82.163 \\
\hline & 0.2 & 6.441 & 24.457 & 25.197 & 46.617 & 64.175 & 68.279 & 81.897 \\
\hline & 0.4 & 6.437 & 23.431 & 25.073 & 44.780 & 62.469 & 67.800 & 78.235 \\
\hline & 0.5 & 6.433 & 22.721 & 24.935 & 43.813 & 58.463 & 67.160 & 73.774 \\
\hline & 0.6 & 6.429 & 21.932 & 24.705 & 42.509 & 51.841 & 66.418 & 71.240 \\
\hline & 0.8 & 6.411 & 20.162 & 23.821 & 35.758 & 45.637 & 64.749 & 67.939 \\
\hline \multirow[t]{6}{*}{$\overline{\mathrm{CSSC}}$} & $\overline{0}$ & 28.557 & 59.919 & 68.320 & 93.546 & 120.854 & 125.943 & 138.384 \\
\hline & 0.2 & 27.960 & 59.509 & 68.025 & 93.300 & 118.325 & 122.765 & 137.670 \\
\hline & 0.4 & 26.556 & 57.122 & 64.642 & 91.131 & 107.910 & 120.953 & 127.870 \\
\hline & 0.5 & 25.802 & 52.780 & 62.059 & 87.969 & 102.021 & 115.684 & 121.543 \\
\hline & 0.6 & 25.121 & 45.965 & 60.632 & 84.066 & 96.957 & 111.674 & 118.161 \\
\hline & 0.8 & 24.077 & 34.149 & 59.451 & 74.311 & 87.789 & 108.820 & 111.469 \\
\hline \multirow[t]{6}{*}{ FFFF } & 0 & 12.757 & 20.291 & 27.106 & 30.288 & 39.289 & 57.549 & 63.667 \\
\hline & 0.2 & 12.747 & 20.092 & 26.438 & 30.272 & 39.282 & 56.848 & 63.654 \\
\hline & 0.4 & 12.712 & 19.262 & 24.952 & 29.994 & 39.139 & 55.593 & 62.469 \\
\hline & 0.5 & 12.677 & 18.467 & 24.280 & 29.564 & 38.901 & 55.138 & 56.889 \\
\hline & 0.6 & 12.622 & 17.402 & 23.787 & 28.745 & 38.403 & 49.311 & 54.797 \\
\hline & 0.8 & 12.283 & 14.765 & 23.227 & 24.950 & 35.131 & 40.194 & 53.670 \\
\hline \multirow[t]{6}{*}{ CSFS } & $\overline{0}$ & 13.264 & 33.432 & 45.129 & $\begin{array}{c}62.104 \\
\end{array}$ & 78.850 & 95.129 & 100.545 \\
\hline & 0.2 & 13.246 & 32.528 & 44.932 & 62.035 & 78.448 & 95.084 & 99.639 \\
\hline & 0.4 & 13.140 & 30.360 & 44.354 & 60.952 & 72.204 & 94.391 & 98.089 \\
\hline & 0.5 & 13.015 & 29.176 & 43.800 & 58.254 & 65.512 & 93.419 & 97.495 \\
\hline & 0.6 & 12.821 & 28.088 & 42.648 & 51.833 & 62.100 & 91.287 & 96.884 \\
\hline & 0.8 & 12.163 & 26.380 & 35.374 & 45.034 & 59.021 & 78.776 & 95.768 \\
\hline \multirow[t]{6}{*}{ SSSS } & 0 & 20.858 & 48.192 & 56.089 & 79.010 & 103.981 & 108.857 & 120.432 \\
\hline & 0.2 & 20.376 & 48.130 & 55.913 & 78.719 & 101.866 & 105.941 & 119.985 \\
\hline & 0.4 & 19.220 & 46.941 & 53.530 & 77.735 & 93.640 & 105.171 & 111.009 \\
\hline & 0.5 & 18.578 & 44.305 & 51.324 & 76.767 & 90.130 & 98.315 & 104.486 \\
\hline & 0.6 & 17.983 & 39.330 & 49.844 & 75.074 & 87.141 & 89.614 & 102.833 \\
\hline & 0.8 & 17.090 & 28.608 & 48.311 & 66.771 & 82.397 & 83.361 & 97.626 \\
\hline
\end{tabular}

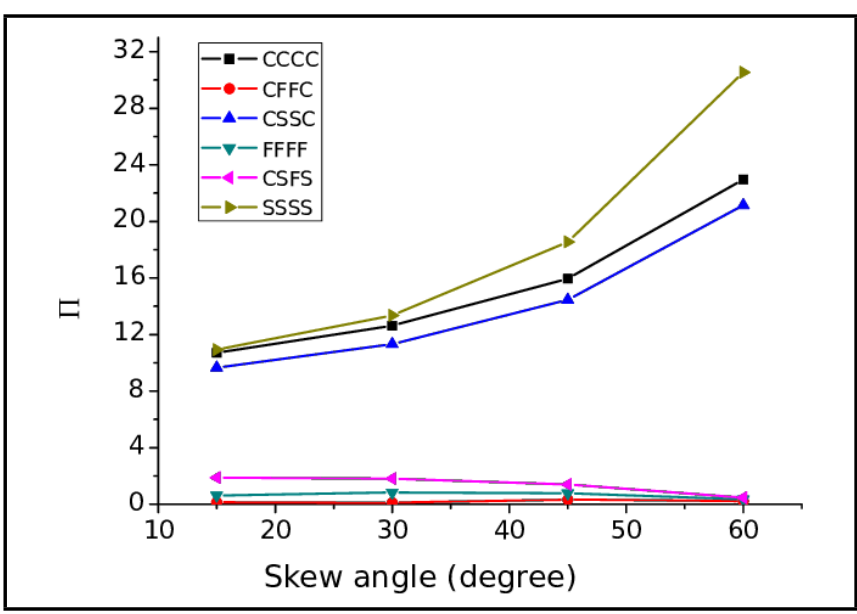

Figure 8. Effect of skew angles on percentage drop in fundamental frequency of rhombic plate for crack ratio of 0.5 .

\section{CONCLUSIONS}

Based on Mindlin plate theory, finite element formulation was carried out to find out natural frequencies of rhombic plate with central through crack. Plates with different skew angles

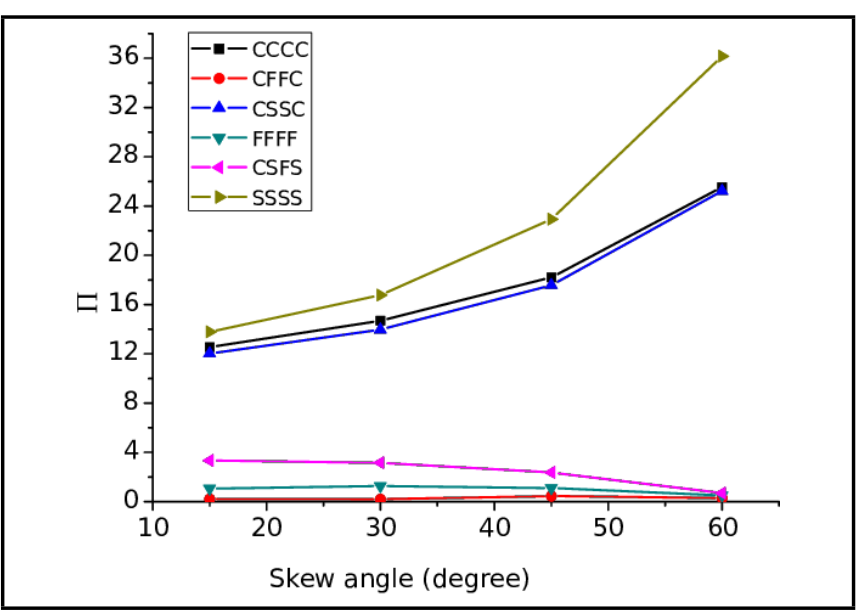

Figure 9. Effect of skew angles on percentage drop in fundamental frequency of rhombic plate for crack ratio of 0.6 .

of $15^{\circ}, 30^{\circ}, 45^{\circ}$, and $60^{\circ}$ under six different combinations of edge conditions i.e. CCCC, CSSC, CFFC, FFFF, CSFS, and SSSS were considered for the analysis. The finite element formulation requires enrichment of elements near crack only, and regular finite elements are used away from the crack. Numer- 
Table 7. Seven non-dimensional frequency parameters $\Omega=\omega a^{2} \sqrt{\rho h / \mathcal{D}}$ of a thin rhombic plate with central horizontal crack under different boundary conditions $\left(h / a=0.001, \nu=0.3, \beta=30^{\circ}\right)$.

\begin{tabular}{|c|c|c|c|c|c|c|c|c|}
\hline \multirow{2}{*}{$\begin{array}{c}\text { Edge } \\
\text { conditions }\end{array}$} & \multirow{2}{*}{$\begin{array}{c}\text { Crack } \\
\text { ratio }\end{array}$} & \multicolumn{7}{|c|}{ Modes } \\
\hline & & 1 & 2 & 3 & 4 & 5 & 6 & 7 \\
\hline \multirow[t]{6}{*}{ CCCC } & 0 & 46.092 & 81.602 & 105.166 & 119.251 & 164.983 & 165.315 & 186.178 \\
\hline & 0.2 & 44.575 & 81.438 & 104.072 & 118.456 & 162.814 & 164.163 & 178.047 \\
\hline & 0.4 & 41.561 & 77.436 & 90.569 & 116.799 & 151.587 & 151.763 & 170.567 \\
\hline & 0.5 & 40.270 & 67.599 & 84.677 & 115.020 & 143.530 & 146.314 & 162.572 \\
\hline & 0.6 & 39.323 & 56.331 & 82.668 & 110.493 & 139.606 & 142.123 & 150.094 \\
\hline & 0.8 & 38.280 & 42.103 & 81.228 & 91.069 & 136.809 & 137.112 & 138.252 \\
\hline \multirow[t]{6}{*}{ CFFC } & 0 & 6.240 & 24.740 & 28.379 & 49.352 & 71.326 & 75.385 & 88.400 \\
\hline & 0.2 & 6.239 & 24.523 & 28.307 & 48.175 & 71.162 & 75.074 & 88.047 \\
\hline & 0.4 & 6.237 & 23.804 & 28.053 & 45.855 & 68.525 & 74.274 & 84.542 \\
\hline & 0.5 & 6.234 & 23.243 & 27.841 & 44.858 & 62.777 & 73.799 & 79.695 \\
\hline & 0.6 & 6.228 & 22.559 & 27.551 & 43.931 & 54.227 & 73.212 & 76.747 \\
\hline & 0.8 & 6.210 & 20.855 & 26.604 & 38.354 & 45.932 & 70.137 & 74.545 \\
\hline \multirow[t]{6}{*}{ CSSC } & $\overline{0}$ & 34.076 & 66.336 & 86.846 & 100.619 & 143.103 & 143.284 & 161.538 \\
\hline & 0.2 & 33.218 & 65.774 & 86.182 & 100.246 & 141.028 & 142.595 & 155.351 \\
\hline & 0.4 & 31.244 & 63.560 & 77.382 & 98.188 & 128.785 & 136.042 & 148.659 \\
\hline & 0.5 & 30.221 & 59.357 & 70.002 & 96.137 & 120.219 & 132.582 & 143.025 \\
\hline & 0.6 & 29.319 & 51.201 & 66.935 & 93.165 & 115.139 & 128.707 & 134.640 \\
\hline & 0.8 & 27.997 & 37.752 & 65.405 & 81.028 & 107.610 & 115.676 & 130.478 \\
\hline \multirow[t]{6}{*}{ FFFF } & 0 & 11.528 & 22.645 & 26.652 & 35.359 & 43.915 & 51.673 & 69.387 \\
\hline & 0.2 & 11.515 & 22.447 & 26.641 & 34.446 & 43.911 & 50.738 & 69.378 \\
\hline & 0.4 & 11.470 & 21.662 & 26.449 & 32.089 & 43.792 & 49.246 & 69.153 \\
\hline & 0.5 & 11.433 & 20.918 & 26.150 & 30.808 & 43.583 & 48.774 & 64.757 \\
\hline & 0.6 & 11.381 & 19.881 & 25.586 & 29.700 & 43.148 & 48.446 & 53.617 \\
\hline & 0.8 & 11.180 & 16.953 & 22.979 & 28.071 & 38.040 & 42.664 & 47.605 \\
\hline \multirow[t]{6}{*}{ CSFS } & 0 & $\overline{c 15.167}$ & 35.940 & 255.433 & 264.950 & 994.530 & 298.868 & 119.633 \\
\hline & 0.2 & 15.144 & 35.004 & 54.769 & 64.893 & 94.018 & 98.471 & 118.255 \\
\hline & 0.4 & 15.024 & 32.704 & 52.669 & 64.060 & 84.246 & 96.974 & 114.864 \\
\hline & 0.5 & 14.892 & 31.424 & 50.529 & 62.818 & 73.159 & 96.019 & 113.174 \\
\hline & 0.6 & 14.687 & 30.228 & 46.662 & 60.210 & 65.877 & 93.845 & 112.030 \\
\hline & 0.8 & 13.986 & 28.289 & 36.405 & 55.392 & 61.793 & 80.695 & 108.799 \\
\hline \multirow[t]{6}{*}{ SSSS } & 0 & 24.900 & 52.624 & 71.720 & $\begin{array}{l}83.808 \\
\end{array}$ & 122.782 & 122.802 & 140.471 \\
\hline & 0.2 & 24.177 & 52.571 & 71.277 & 83.291 & 121.400 & 122.388 & 134.751 \\
\hline & 0.4 & 22.492 & 51.558 & 65.151 & 82.200 & 114.064 & 116.184 & 128.945 \\
\hline & 0.5 & 21.575 & 49.221 & 58.976 & 81.479 & 108.988 & 109.865 & 125.459 \\
\hline & 0.6 & 20.725 & 43.599 & 55.101 & 80.154 & 103.789 & 106.302 & 118.402 \\
\hline & 0.8 & 19.394 & 31.084 & 52.501 & 71.933 & 99.697 & 100.951 & 102.427 \\
\hline
\end{tabular}

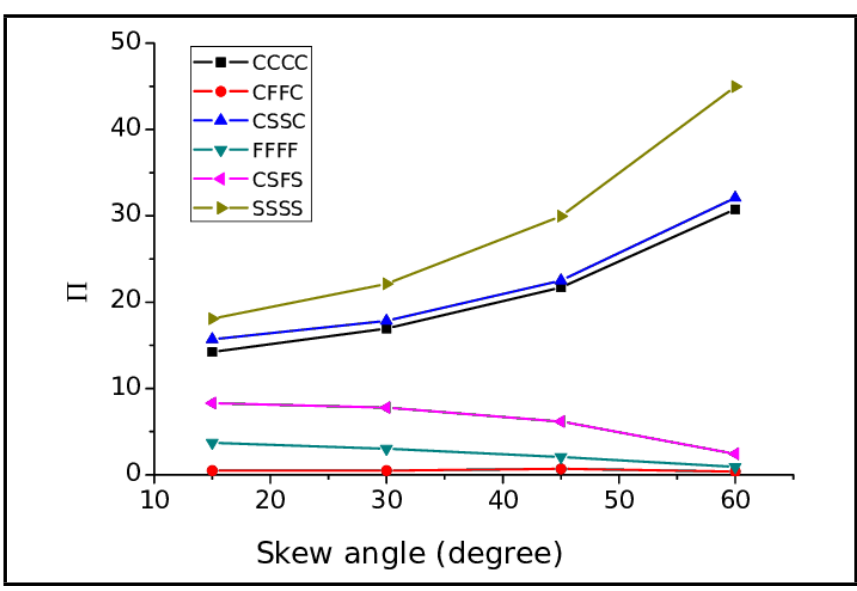

Figure 10. Effect of skew angles on percentage drop in fundamental frequency of rhombic plate for crack ratio of 0.8 .

ical results obtained were shown extensively in the form of table to show the effect of crack and skew angle on natural frequencies of the rhombic plate. Most of the results presented forrhombic plate with central crack are first reported in literature. From the investigation of computed results of natural

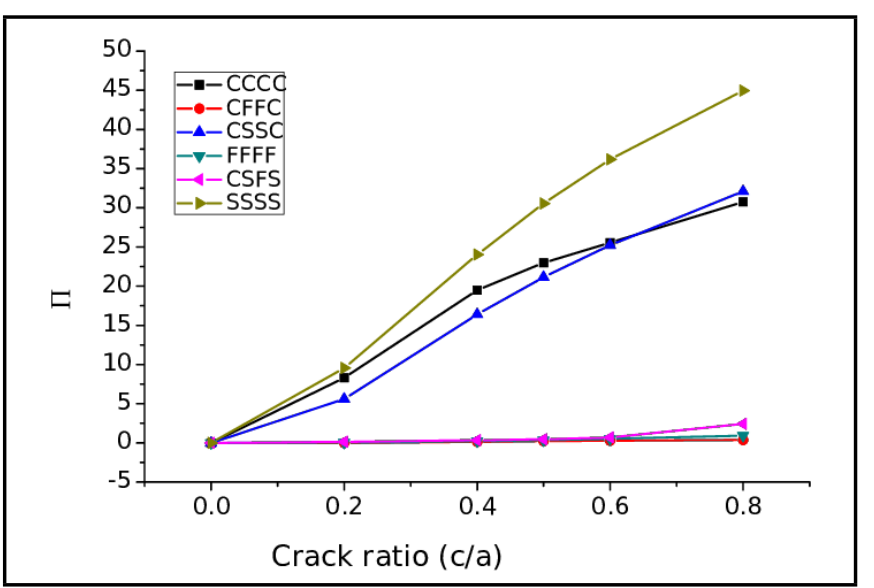

Figure 11. Effect of crack ratio on percentage drop in fundamental frequency of rhombic plate with skew angle $60^{\circ}$

frequencies following may be concluded.

(i) Natural frequency decreases with an increase in the crack length irrespective of the edge conditions and skew angles of rhombic plate.

(ii) The percentage drop in fundamental frequency increases 
Table 8. Seven non-dimensional frequency parameters $\Omega=\omega a^{2} \sqrt{\rho h / \mathcal{D}}$ of a thin rhombic plate with central horizontal crack under different boundary conditions $\left(h / a=0.001, \nu=0.3, \beta=45^{\circ}\right)$.

\begin{tabular}{|c|c|c|c|c|c|c|c|c|}
\hline \multirow{2}{*}{$\begin{array}{c}\text { Edge } \\
\text { conditions }\end{array}$} & \multirow{2}{*}{$\begin{array}{l}\text { Crack } \\
\text { ratio }\end{array}$} & \multicolumn{7}{|c|}{ Modes } \\
\hline & & 1 & 2 & 3 & 4 & 5 & 6 & 7 \\
\hline \multirow[t]{6}{*}{$\mathrm{CCCC}$} & 0 & 65.651 & 106.507 & 148.327 & 157.249 & 196.793 & 229.510 & 248.421 \\
\hline & 0.2 & 62.633 & 106.237 & 147.085 & 153.059 & 195.871 & 226.406 & 248.151 \\
\hline & 0.4 & 57.249 & 99.028 & 114.724 & 145.596 & 189.257 & 210.111 & 236.805 \\
\hline & 0.5 & 55.179 & 82.266 & 107.290 & 143.419 & 186.538 & 193.521 & 218.255 \\
\hline & 0.6 & 53.690 & 68.222 & 104.949 & 135.927 & 174.081 & 184.747 & 207.782 \\
\hline & 0.8 & 51.398 & 53.494 & 102.173 & 109.115 & 165.118 & 175.791 & 199.426 \\
\hline \multirow[t]{6}{*}{ CFFC } & $\overline{0}$ & 6.208 & 25.738 & 34.301 & $\begin{array}{l}55.638 \\
\end{array}$ & 82.877 & 85.599 & 118.513 \\
\hline & 0.2 & 6.203 & 25.613 & 34.224 & 54.150 & 81.372 & 85.427 & 117.833 \\
\hline & 0.4 & 6.194 & 25.160 & 33.893 & 51.095 & 77.760 & 83.443 & 107.065 \\
\hline & 0.5 & 6.187 & 24.764 & 33.578 & 49.848 & 71.625 & 80.843 & 94.309 \\
\hline & 0.6 & 6.179 & 24.229 & 33.161 & 48.999 & 61.243 & 79.346 & 90.040 \\
\hline & 0.8 & 6.164 & 22.671 & 31.994 & 45.408 & 49.270 & 76.505 & 86.534 \\
\hline \multirow[t]{6}{*}{$\overline{\mathrm{CSSC}}$} & 0 & 477.503 & 85.181 & 122.860 & 128.928 & 167.599 & 197.691 & 215.139 \\
\hline & 0.2 & 45.887 & 84.025 & 122.396 & 126.698 & 166.373 & 194.604 & 214.384 \\
\hline & 0.4 & 42.365 & 80.843 & 99.196 & 120.924 & 163.277 & 170.559 & 205.581 \\
\hline & 0.5 & 40.640 & 73.811 & 85.870 & 118.972 & 159.669 & 161.235 & 194.883 \\
\hline & 0.6 & 39.152 & 61.801 & 82.852 & 115.134 & 147.843 & 157.450 & 180.601 \\
\hline & 0.8 & 36.805 & 46.109 & 80.667 & 96.183 & 133.951 & 149.627 & 164.560 \\
\hline \multirow[t]{6}{*}{ FFFF } & 0 & 10.499 & 24.032 & 27.761 & 441.766 & 51.521 & 61.518 & 66.930 \\
\hline & 0.2 & 10.484 & 24.027 & 27.534 & 4.171 & 51.484 & 57.729 & 66.889 \\
\hline & 0.4 & 10.446 & 23.902 & 26.696 & 41.360 & 50.398 & 50.849 & 66.233 \\
\hline & 0.5 & 10.418 & 23.703 & 25.894 & 40.761 & 47.507 & 49.684 & 65.065 \\
\hline & 0.6 & 10.383 & 23.320 & 24.741 & 39.597 & 45.793 & 47.044 & 61.776 \\
\hline & 0.8 & 10.279 & 21.210 & 21.433 & 36.139 & 37.486 & 44.678 & 54.080 \\
\hline \multirow[t]{6}{*}{ CSFS } & $\overline{0}$ & 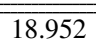 & 243.493 & $\begin{array}{l}69.993 \\
\end{array}$ & 84.209 & 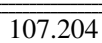 & 133.078 & 2144.920 \\
\hline & 0.2 & 18.923 & 42.234 & 68.690 & 83.672 & 106.905 & 131.040 & 144.001 \\
\hline & 0.4 & 18.807 & 38.996 & 65.327 & 80.687 & 98.733 & 113.474 & 141.119 \\
\hline & 0.5 & 18.688 & 37.070 & 61.916 & 76.476 & 86.231 & 109.697 & 139.794 \\
\hline & 0.6 & 18.501 & 35.123 & 55.642 & 71.355 & 80.289 & 107.409 & 136.444 \\
\hline & 0.8 & 17.780 & 31.308 & 43.378 & 67.012 & 74.360 & 93.673 & 115.036 \\
\hline \multirow[t]{6}{*}{ SSSS } & 0 & 34.935 & $\overline{c 66.266}$ & 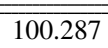 & 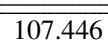 & 140.766 & 168.275 & 185.066 \\
\hline & 0.2 & 33.386 & 66.180 & 99.442 & 105.650 & 140.352 & 166.561 & 184.824 \\
\hline & 0.4 & 30.137 & 64.733 & 85.583 & 98.356 & 136.268 & 157.204 & 181.536 \\
\hline & 0.5 & 28.456 & 61.038 & 72.007 & 97.814 & 133.685 & 149.036 & 170.170 \\
\hline & 0.6 & 26.928 & 51.882 & 66.652 & 96.445 & 131.794 & 136.014 & 157.590 \\
\hline & 0.8 & 24.467 & 35.903 & 62.924 & 84.747 & 113.749 & 128.842 & 146.347 \\
\hline
\end{tabular}

for SSSS, CCCC, and CSSC rhombic plates with an increase in skew angles at agiven crack ratio.

(iii) With a small crack ratio of $c / a \approx 0.2$, the percentage drop in fundamental frequency is very small for CFFC, CSFC and FFFF rhombic plate at different skew angles.

(iv) central crack with $c / a=0.8$ reduces the fundamental frequency only by $0.7 \%$ in relation to that of intact plate under CFFC edge condition of the rhombic plate.

(v) Fundamental frequency of rhombic intact plate remains almost the same with variation of skew angle (up to $60^{\circ}$ has been considered in this paper) under CFFC conditions.

Although rhombic thin plate with crack were analysed herein, present methodology can be applied to treat thick plate, as the formulation is based on Mindlin plate theory, which is suitable for moderately thick plate. This approach can be applied to treat other shape of plates such as triangular plate and skew trapezoidal plate with central crack and side crack. Fur- thermore, it will be interesting to extend the methodology to analyse vibration of rhombic plate with multiple cracks.

\section{REFERENCES}

1 Leissa, A. W. Vibration of Plates, NASA SP-160, (1969).

2 Leissa, A. W. Recent research in plate vibrations: classical theory, Shock and Vibration Digest, 9 (10), 13-24, (1977). https://dx.doi.org/10.1177/058310247700901005

3 Leissa, A. W. Plate vibrations research 1976-1980: classical theory, Shock and Vibration Digest, 13 (9), 11-22, (1981). https://dx.doi.org/10.1177/058310248101300905

4 Leissa, A. W. Recent studies in plate vibrations 1981-1985: part I classical theory, Shock and Vibration Digest, 19 (2), 11-18, (1987). https://dx.doi.org/10.1177/058310248701900204

5 Raju, K. K. and Hinton, E. Natural frequencies and modes of rhombic Mindlin plates, Earthquake Engi- 
Table 9. Seven non-dimensional frequency parameters $\Omega=\omega a^{2} \sqrt{\rho h / \mathcal{D}}$ of a thin rhombic plate with central horizontal crack under different boundary conditions $\left(h / a=0.001, \nu=0.3, \beta=60^{\circ}\right)$.

\begin{tabular}{|c|c|c|c|c|c|c|c|c|}
\hline \multirow{2}{*}{$\begin{array}{c}\text { Edge } \\
\text { conditions }\end{array}$} & \multirow{2}{*}{$\begin{array}{c}\text { Crack } \\
\text { ratio }\end{array}$} & \multicolumn{7}{|c|}{ Modes } \\
\hline & & 1 & 2 & 3 & 4 & 5 & 6 & 7 \\
\hline \multirow[t]{6}{*}{ CCCC } & 0 & 121.634 & 177.710 & 231.729 & 291.496 & 304.732 & 354.605 & 408.631 \\
\hline & 0.2 & 111.551 & 176.693 & 228.965 & 274.824 & 290.684 & 352.587 & 402.563 \\
\hline & 0.4 & 97.892 & 143.800 & 173.680 & 227.108 & 284.435 & 317.562 & 354.314 \\
\hline & 0.5 & 93.689 & 115.401 & 166.869 & 218.476 & 261.612 & 282.844 & 345.846 \\
\hline & 0.6 & 90.561 & 99.442 & 161.912 & 192.595 & 242.599 & 279.334 & 339.564 \\
\hline & 0.8 & 84.234 & 84.738 & 150.689 & 153.096 & 234.136 & 240.889 & 320.358 \\
\hline \multirow[t]{6}{*}{ CFFC } & 0 & 6.295 & 27.006 & 46.597 & 63.790 & 107.167 & 114.220 & 145.075 \\
\hline & 0.2 & 6.294 & 26.958 & 46.506 & 62.953 & 102.034 & 114.109 & 141.328 \\
\hline & 0.4 & 6.287 & 26.758 & 45.855 & 60.759 & 94.149 & 112.014 & 131.626 \\
\hline & 0.5 & 6.281 & 26.555 & 45.223 & 59.628 & 91.024 & 101.283 & 118.103 \\
\hline & 0.6 & 6.277 & 26.241 & 44.452 & 58.717 & 82.245 & 93.206 & 114.823 \\
\hline & 0.8 & 6.272 & 25.151 & 42.644 & 57.508 & 63.970 & 89.585 & 106.073 \\
\hline \multirow[t]{6}{*}{ CSSC } & $\overline{0}$ & 884.414 & $\overline{0138.420}$ & 2186.641 & 241.274 & 245.539 & 298.881 & 348.093 \\
\hline & 0.2 & 79.703 & 134.115 & 185.841 & 231.954 & 238.958 & 297.195 & 332.758 \\
\hline & 0.4 & 70.576 & 125.615 & 137.924 & 182.024 & 236.596 & 271.310 & 296.207 \\
\hline & 0.5 & 66.570 & 103.329 & 128.387 & 177.009 & 222.585 & 243.607 & 292.353 \\
\hline & 0.6 & 63.117 & 86.124 & 125.168 & 165.901 & 196.519 & 235.604 & 286.895 \\
\hline & 0.8 & 65.413 & 67.431 & 115.618 & 132.024 & 186.104 & 207.807 & 253.912 \\
\hline \multirow[t]{6}{*}{ FFFF } & 0 & 9.779 & 22.265 & 39.296 & 39.854 & 62.674 & 68.575 & 89.716 \\
\hline & 0.2 & 9.774 & 22.264 & 39.074 & 39.850 & 62.646 & 68.398 & 89.630 \\
\hline & 0.4 & 9.756 & 22.190 & 38.111 & 39.834 & 61.842 & 65.905 & 82.659 \\
\hline & 0.5 & 9.744 & 22.067 & 37.118 & 39.813 & 58.668 & 64.064 & 74.426 \\
\hline & 0.6 & 9.729 & 21.820 & 35.607 & 39.720 & 51.788 & 63.441 & 67.722 \\
\hline & 0.8 & 9.688 & 20.438 & 30.684 & 37.726 & 38.728 & 57.467 & 62.805 \\
\hline \multirow[t]{6}{*}{ CSFS } & $\overline{0}$ & 26.198 & $\overline{262.600}$ & 97.101 & 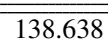 & 2146.379 & 186.903 & 224.672 \\
\hline & 0.2 & 26.160 & 60.780 & 92.554 & 137.830 & 144.251 & 185.604 & 216.414 \\
\hline & 0.4 & 26.106 & 55.084 & 85.665 & 119.518 & 134.927 & 151.919 & 186.292 \\
\hline & 0.5 & 26.075 & 50.935 & 83.221 & 96.445 & 129.277 & 143.653 & 183.574 \\
\hline & 0.6 & 26.017 & 46.219 & 79.240 & 83.078 & 122.589 & 139.593 & 171.937 \\
\hline & 0.8 & 25.561 & 37.044 & 64.946 & 78.083 & 110.095 & 127.456 & 134.808 \\
\hline \multirow[t]{6}{*}{ SSSS } & 0 & 263.929 & 2104.912 & 2148.011 & 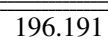 & 208.840 & 248.963 & 293.411 \\
\hline & 0.2 & 57.811 & 104.621 & 145.777 & 194.042 & 196.826 & 247.203 & 290.553 \\
\hline & 0.4 & 48.565 & 99.975 & 117.919 & 144.641 & 191.820 & 242.463 & 259.587 \\
\hline & 0.5 & 44.403 & 84.542 & 101.054 & 143.882 & 189.790 & 209.546 & 246.597 \\
\hline & 0.6 & 40.804 & 66.881 & 95.846 & 140.061 & 173.163 & 188.703 & 240.717 \\
\hline & 0.8 & 35.185 & 45.822 & 86.961 & 110.706 & 148.040 & 180.740 & 220.645 \\
\hline
\end{tabular}

neering and Structural Dynamics, 8, 55-62, (1980). https://dx.doi.org/10.1002/eqe.4290080106

${ }^{6}$ Durvasula, S. Free vibration of simply supported parallelogrammic plates, Journal of Aircraft, 6 (1), 61-68, (1969). https://dx.doi.org/10.2514/3.44005

7 Durvasula, S. Natural frequencies and modes of clamped skew plates, American Institute of Aeronautics and Astronautics Journal, 7 (6), 1164-1166, (1969). https://dx.doi.org/10.2514/3.5296

${ }^{8}$ Liew, K. M. and Lam, K. Y. Application of two dimensional orthogonal plate function to flexural vibrations of skew plates, Journal of Sound and Vibration, 139 (2), 241-252, (1990). https://dx.doi.org/10.1016/0022-460X(90)90885-4

${ }^{9}$ Liew K. M., Xiang Y., Kitipornchai, S., and Wang, C. M. Vibration of thick skew plates based on Mindlin shear deformation plate theory, Journal of Sound and Vibration, 168 (1), 39-69, (1993). https://dx.doi.org/10.1006/jsvi.1993.1361
10 Basu, P. K., Rossow, M. P., and Szabo, B. A. Theoretical Manual and Users Guide for COMET-X, Report FRA/ORD-77/60, Washington University, (1977).

11 McGee, O. G. and Leissa, A. W. Three-dimensional free vibrations of thick skewed cantilevered plates, Journal of Sound and Vibration, 144 (2), 305-322, (1991). https://dx.doi.org/10.1016/0022-460X(91)90751-5

${ }^{12}$ McGee, O. G., Leissa, A. W., and Huang, S.Vibrations of cantilevered skewed plates with corner stress singularities, International Journal for Numerical Methods in Engineering, 35 (2), 409-424, (1992). https://dx.doi.org/10.1002/nme.1620350211

${ }^{13}$ Huang, C. S., McGee, O. G., Leissa, A. W., and Kim, J.W. Accurate vibration analysis of simply supported rhombic plates by considering stress singularities, Journal of Vibration and Acoustics, 117 (3A), 245-251, (1995). https://dx.doi.org/10.1115/1.2874440

${ }^{14}$ McGee, O. G., Kim, J. W., Kim, Y. S., and Leissa, A. W. Corner stress singularity effects on the vibration of rhombic 
plates with combinations of clamped and simply supported edges, Journal of Sound and Vibration, 193 (3), 555-580, (1996). https://dx.doi.org/10.1006/jsvi.1996.0302

15 McGee, O. G., Kim, J. W., and Leissa A. W. The influence of corner stress singularities on the vibration characteristics of rhombic plates with combinations of simply supported and free edges, Int. J. Mech. Sc., 41 (1), 17-41, (1999). https://dx.doi.org/10.1016/S0020-7403(97)00120-3

16 Woo, K. S., Hong, C. H., Basu, P. K., and Seo, C. G. Free vibration of skew plates by p-version of F. E.M., Journal of Sound and Vibration, 268 (4), 637-656, (2003). https://dx.doi.org/10.1016/S0022-460X(02)01536-5

17 Zhou, L. and Zheng, W. X. Vibration of skew plates by the MLS-Ritz method, Internal Journal of Mechanical Sciences, 50 (7), 1133-1141, (2008). https://dx.doi.org/10.1016/j.ijmecsci.2008.05.002

${ }^{18}$ Mizusawa, T. and Kondo, Y. Application of the spline element method to analyze vibration of skew Mindlin plates with varying thickness in one direction, Journal of Sound and Vibration, 241 (3), 485-501, (2001). https://dx.doi.org/10.1006/jsvi.2000.3303

19 Malekzadeh, P. and Karami, G. Polynomial and harmonic differential quadrature methods for free vibration of variable thickness thick skew plates, Engineering Structures, 27 (10), 1563-74, (2005). https://dx.doi.org/10.1016/j.engstruct.2005.03.017

${ }^{20}$ Zhou, D., Lo, S. H., Au F. T. K., Cheung Y. K., and Liu W. Q. 3-D vibration analysis of skew thick plates using plates using Chebyshev-Ritz method, International Journal of Mechanical Sciences, 48 (12), 1481-93, (2006). https://dx.doi.org/10.1016/j.ijmecsci.2006.06.015

${ }^{21}$ Lai, S. K., Zhou, L., Zhang, Y. Y., and Xiang, Y. Application of the DSC-Element method to flexural vibration of skew plates with continuous and discontinuous boundaries, Thin-Walled Structures, 49 (9), 1080-1090, (2011). https://dx.doi.org/10.1016/j.tws.2011.03.019

22 Wang, X. and $\mathrm{Wu}, \mathrm{Z}$. Differential quadrature analysis of free vibration of rhombic plates with free edges, Applied Mathematics and Computation, 225, 171-183, (2013). https://dx.doi.org/10.1016/j.amc.2013.09.018

${ }^{23}$ Wang, X., Wang, Y., and Yuan, Z. Accurate vibration analysis of skew plates by the new version of the differential quadrature method, Applied Mathematical Modelling, 38 (3), 926-937, (2014). https://dx.doi.org/10.1016/j.apm.2013.07.021

${ }^{24}$ Stahl, B. and Keer, L. M. Vibration and stability of cracked rectangular plates, International Journal of Solids and Structure, 8 (1), 69-91, (1972). https://dx.doi.org/10.1016/0020-7683(72)90052-2
${ }^{25}$ Huang, C. S. and Leissa, A. W. Vibration analysis of rectangular plates with side cracks via the Ritz method, Journal of Sound and Vibration, 323 (3-5), 974-988, (2009). https://dx.doi.org/10.1016/j.jsv.2009.01.018

${ }^{26}$ Huang, C. S., Leissa, A. W., and Chan, C. W. Vibrations of rectangular plates with internal cracks or slits, Internal Journal of Mechanical Sciences, 53 (6), 436-445, (2011). https://dx.doi.org/10.1016/j.ijmecsci.2011.03.006

27 Bachene, M., Tiberkak, R., and Rechak, S. Vibration analysis of cracked plates using the extended finite element method, Archive of Applied Mechanics, 79 (3), 249-262, (2009). https://dx.doi.org/10.1007/s00419-008-0224-7

${ }^{28}$ Israr, A., Manoach, E., Trendafilova, I., Ostachowicz, M., Krawczuk, M., and Zak, A. Analytical modeling and vibration analysis of partially cracked rectangular plates with different boundary conditions and loading, Journal of Applied Mechanics, 76, (2009). https://dx.doi.org/10.1115/1.2998755

${ }^{29}$ Ismail, R. and Cartmell, M. P. An investigation into the vibration analysis of a plate with a surface crack of variable angular orientation, Journal of Sound and Vibration, 331 (12), 2929-2948, (2012). https://dx.doi.org/10.1016/j.jsv.2012.02.011

30 Joshi, P. V., Jain, N. K., and Ramtekkar, G. D. Analytical modeling and vibration analysis of internally cracked rectangular plates, Journal of Sound and Vibration, 333 (22), 5851-5856, (2014). https://dx.doi.org/10.1016/j.jsv.2014.06.028

${ }^{31}$ Liew, K. M., Hung, K. C., and Lim, M. K. A solution method for analysis of cracked plates under vibration, $E n$ gineering Fracture Mechanics, 48 (3), 393-404, (1994). https://dx.doi.org/10.1016/0013-7944(94)90130-9

32 Moes, N., Dolbow. J., and Belytschko, T. A finite element method for crack growth without remeshing, International Journal of Numerical Methods in Engineering, 46 (1), 131-50, (1999). https://dx.doi.org/10.1002/(SICI)10970207(19990910)46:1\%3C131::AIDNME726\%3E3.3.CO;2-A

${ }^{33}$ Bardell, N. S. The free vibration of skew plates using the hierarchical finite element method, Computers \& Structures, 45 (5-6), 841-74, (1992). https://dx.doi.org/10.1016/00457949(92)90044-Z

${ }^{34}$ Singh, B. and Chakraverty, S. Flexural vibration of skew plates using boundary characteristic orthogonal polynomials in two variables, Journal of Sound and Vibration, 173 (2), 157-178. (1994) https://dx.doi.org/10.1006/jsvi.1994.1224 